\title{
Correction to: Interior-Exterior Ambiances: Environmental Transitions in the Recollection of an Urban Stroll
}

Claude M. H. Demers and André Potvin

\section{Correction to:}

Chapter 14 in: B. E. A. Piga et al. (eds.), Experiential Walks for Urban Design, Springer Tracts in Civil Engineering, https://doi.org/10.1007/978-3-030-76694-8_14

The book was inadvertently published with badly cut images $14.1,14.2,14.3,14.4$, $14.5,14.6$ in chapter 14.

These images has now been updated with the correction chapter. 


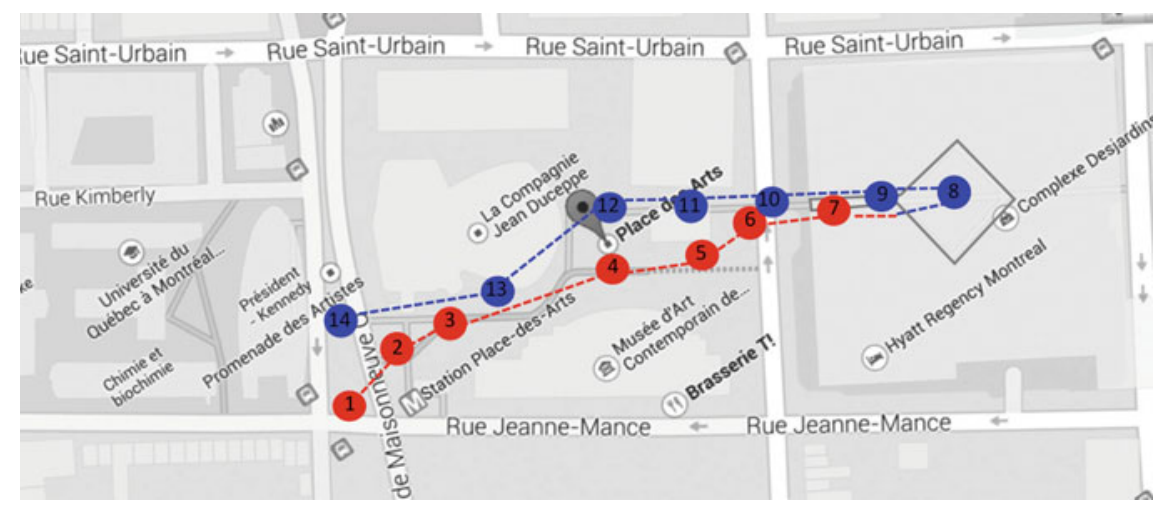

Fig. 14.1 Walking itinerary and stops: ground level (red) and underground level (blue). Source Demers and Potvin

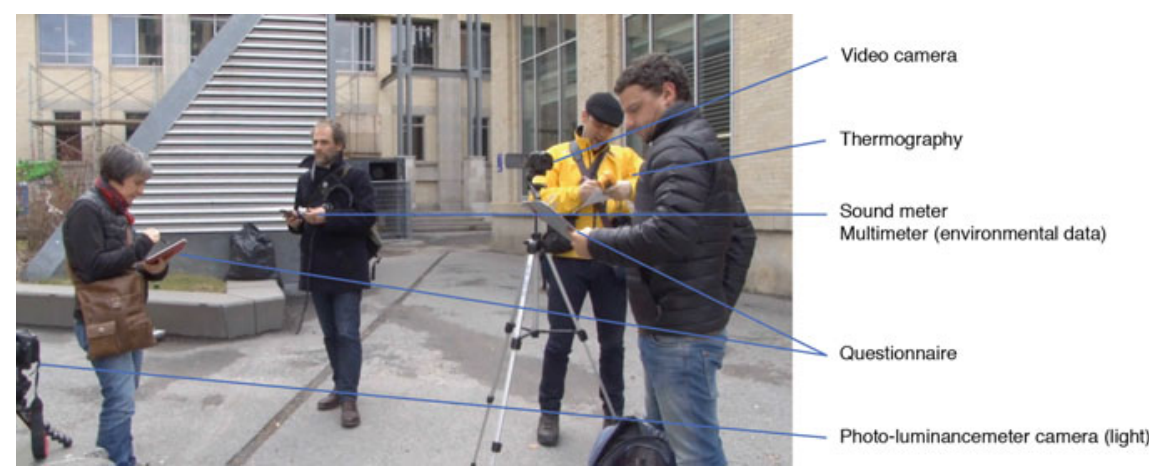

Fig. 14.2 Researchers and environmental tools of data acquisition acting as a "sensing machine". Source International ambiances network 


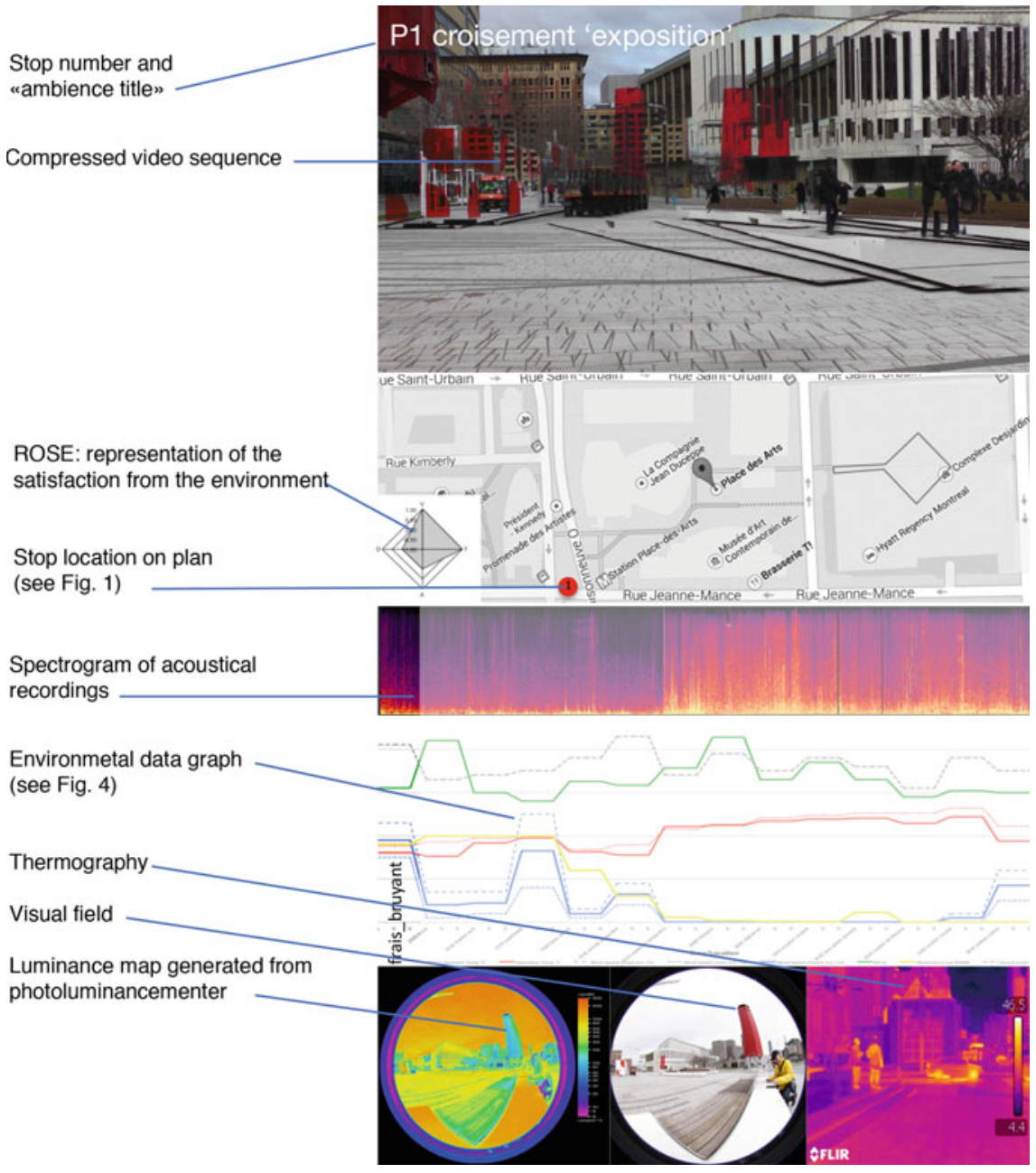

Fig. 14.3 Fact sheet of data representation of captured ambiances at stop P1. Source Demers 


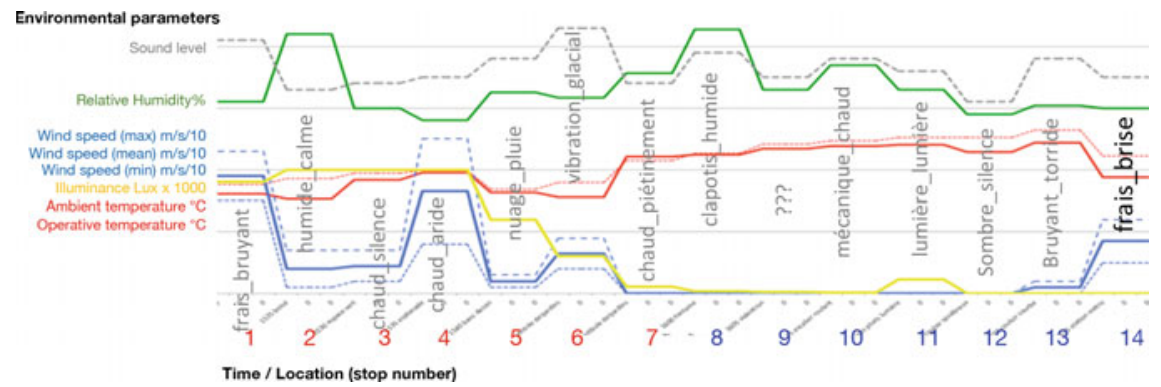

Fig. 14.4 Environmental transitions and survey parameters through time and location. Source Potvin
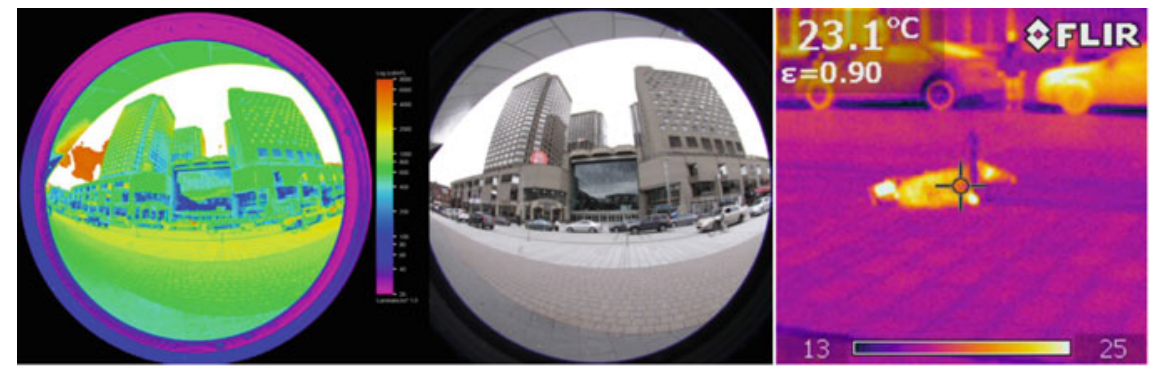

(a)

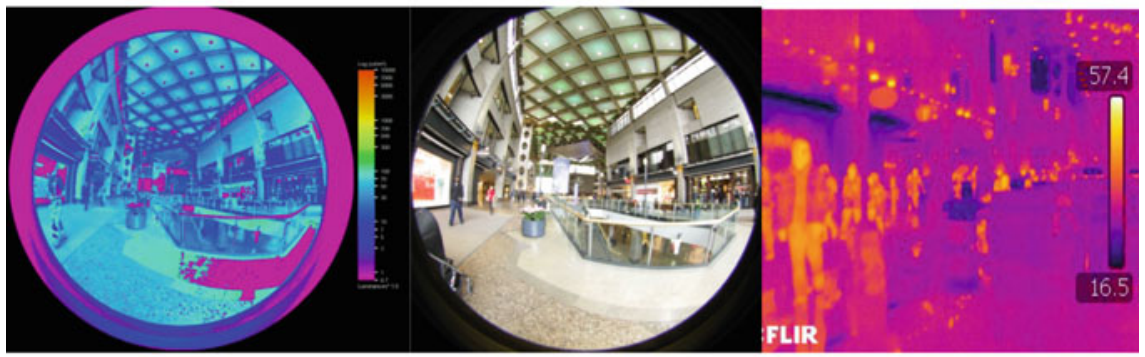

(b)

Fig. 14.5 Interior-exterior transition: a Ste-Catherine Street stop 6; b Complexe Desjardins stop 7. Source Demers and Potvin 


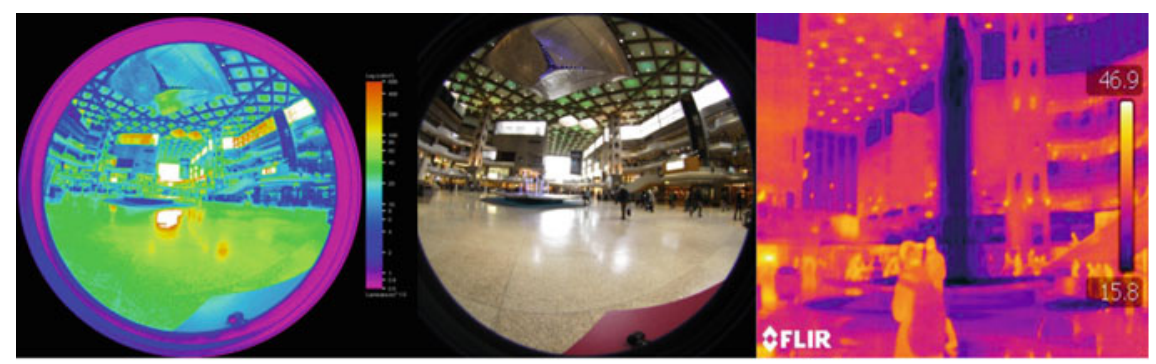

(a)

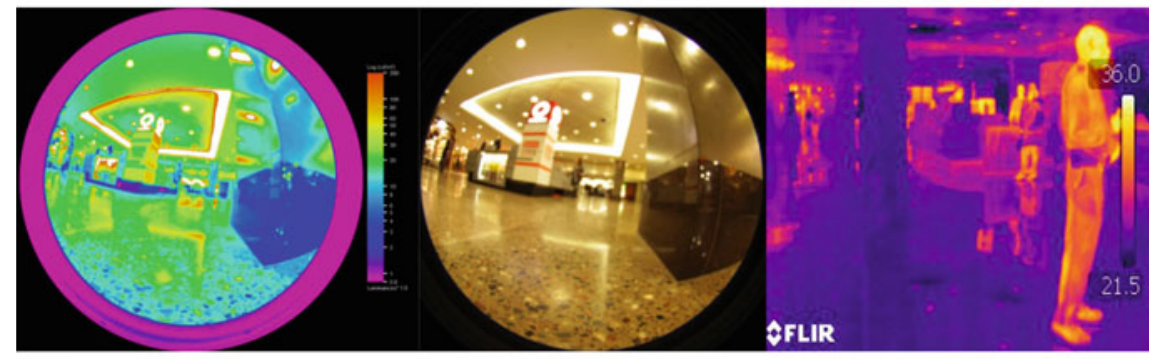

(b)

Fig. 14.6 Ground to underground transition a ground floor stop 8; b underground stop 9. Source Demers and Potvin 